See discussions, stats, and author profiles for this publication at: https://www.researchgate.net/publication/323522745

\title{
Compassion and Emotional Worlds in Early Childhood Education
}

Chapter · June 2018

DOI: 10.4324/9780203732052-11

\section{CITATIONS}

2

3 authors:

Lasse Lipponen

4. University of Helsinki 112 PUBLICATIONS 3,651 CITATIONS

SEE PROFILE

(a) Jaakko Hilppö

University of Helsinki

36 PUBLICATIONS 260 CITATIONS

SEE PROFILE
READS

207

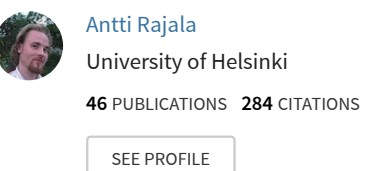

Some of the authors of this publication are also working on these related projects:

Vital Voices for Vital Years 2: Perspectives on Early Childhood Development in Singapore. Funded by Lien Foundation, Singapore. View project

Interview Series on the role of theory and philosophy in educational science: SIG 25 Newspaper, EARLI View project 
Lipponen, L., Rajala, A., Hilppö, J. (2018). Compassion and emotional worlds in early childhood education. In C. A. Pascal, T. Bertram, \& M. Veisson (Eds.), Early Childhood Education and Change in Diverse Cultural Contexts. Routledge

\title{
Compassion and Emotional Worlds in Early Childhood Education
}

Lasse Lipponen1, Antti Rajala1 \& Jaakko Hilppö2

1Department of Educational Sciences, University of Helsinki

2Northwestern University, Evanston

\begin{abstract}
In this chapter, we identify and explore three perspectives for researching and understanding compassion in early education settings, namely, the psychological, practice, and cultures of compassion perspectives. We argue that understanding such a complex phenomenon as compassion requires going beyond the psychological and practice perspectives to focus on and transform systemic or institutional causes of collective suffering. We need to harness compassion as a tool for social transformation - not only on the level of small group, face-to-face interactions (practices), but also on the level of large-scale social processes and policies.
\end{abstract}

\section{Introduction}

It is morning in the Children's House kindergarten, and a father is dropping off his daughter. It appears that this morning, for some reason, the child is finding it difficult to let her father go. She stays in her father's lap, holding him very tightly. 
Lipponen, L., Rajala, A., Hilppö, J. (2018). Compassion and emotional worlds in early childhood education. In C. A. Pascal, T. Bertram, \& M. Veisson (Eds.), Early Childhood Education and Change in Diverse Cultural Contexts. Routledge

A teacher is also present, but she only observes what is happening. After a few moments, the teacher approaches the father and the child, and asks the child very gently if she could hold her. The child looks at the teacher, but stays in her father's arms. The father turns to the teacher and tells her that the child would like to draw. Immediately, the child gets off her father's lap, goes to the teacher, and together they go get the necessary materials for drawing. They go to the table and the child starts to draw. The teacher sits very close to the child, not saying anything, just watching what she is doing. The father leaves.

This vignette draws attention to the emotional worlds of early childhood education settings. Missing parents, getting oneself hurt, longing for friends, feeling bad because of name calling, or being excluded from play activities are an evident part of these emotional worlds. In this chapter, we frame experiences such as these as suffering in the context of early childhood education (ECE). More specifically by suffering we refer to "a wide range of unpleasant subjective experiences including physical and emotional pain, psychological distress and existential anguish” (Lilius et al., 2011, 874).

Although we cannot (and sometimes even should not) prevent children from going through unpleasant experiences and events, we-children and adultscertainly have the opportunity to decide how to respond when we become aware of such situations: whether we ignore the suffering or take action to alleviate the pain. Noticing that somebody is suffering, and making the judgment that the situation is important and not trivial (Nussbaum, 2014), potentially leads to the 
Lipponen, L., Rajala, A., Hilppö, J. (2018). Compassion and emotional worlds in early childhood education. In C. A. Pascal, T. Bertram, \& M. Veisson (Eds.), Early Childhood Education and Change in Diverse Cultural Contexts. Routledge

experience of empathic concern towards the sufferer. In some cases, one may even try to do something concrete to alleviate the situation; that is, act in a compassionate way. Empathy and compassion are two core emotions when we think about the social relation between those who suffer and those who try to alleviate suffering. They are also perhaps the most powerful emotions at play in the emotional worlds of early childhood education.

Interestingly, research on compassion in early childhood education settings is scarce. Our own earlier work (Paananen \& Lipponen, in press) demonstrates that supporting compassion is not a top priority in the development of early childhood education or in the practices of kindergartens. On the contrary, aims to support or foster compassion are systematically dismissed when they conflict with other aims. This happens especially when decision-making practices are engulfed in the discourse of individualistic rights and different governance measures narrow what teachers see as possible or policy sanctioned actions in practice (Paananen in press). While our work begins to pave the way for the compassion as a pedagogical priority, we still lack a wide-ranging investigation of its significance for democratic politics and know surprisingly little about the political contexts of compassion in ECE settings.

The importance of compassion in ECE settings is both timely and timeless. It is timeless because compassion is a moral response to suffering and pain, which are always evident in human life and relations, as noted already by such classical authors as Aristotle and Rousseau. Compassion is timely as a civic capacity since the world's growing interdependency and the development of communication 
Lipponen, L., Rajala, A., Hilppö, J. (2018). Compassion and emotional worlds in early childhood education. In C. A. Pascal, T. Bertram, \& M. Veisson (Eds.), Early Childhood Education and Change in Diverse Cultural Contexts. Routledge

technology is bringing people across remote parts of the world in contact at unprecedented scale. Thus, people regularly encounter suffering caused by economic crises, natural catastrophes, or wars in remote parts of the world. Compassion can help to counter polarization and foster human response to suffering in an interconnected world (Rynes, Bartunek, Dutton, \& Margolis, 2012; Tronto, 2013; Morrell, 2010). Compassion is also important in the working life. Compassion increases positive emotions and commitment to work (Frost, Dutton, Worline, \& Wilson, 2000; Lilius et al., 2008) and it is important for an innovative work community (Dutton \& Worline, 2017; Patnaik, 2009). These arguments are reflected in the shifts in ECE policy towards increased recognition of the importance of compassion. For example, OECD has characterized compassion as an essential global competence (OECD, 2015; 2016). Similarly, in Finland, the new National Core Curriculum guides ECEC professionals to foster children's compassionate and caring orientation towards others (EDUFI, 2016).

The existing research and educational programs related to compassion mainly address social and emotional learning. These studies and programs are often premised on individualistic assumptions and involve intervention programs and curricula for promoting emotional skills, and self-regulation strategies for children to express their emotions (Madrid, Fernie, \& Kantor, 2015; Vadeboncoeur \& Collie, 2013). These studies, often based on a psychological perspective of studying and understanding of emotions, demonstrate the importance of the role emotions play in children's learning, development and wellbeing. Another, less 
Lipponen, L., Rajala, A., Hilppö, J. (2018). Compassion and emotional worlds in early childhood education. In C. A. Pascal, T. Bertram, \& M. Veisson (Eds.), Early Childhood Education and Change in Diverse Cultural Contexts. Routledge

prominent perspective for researching emotions is a practice perspective. This perspective draws attention to how emotions are constructed, enacted, and negotiated in everyday social interactions in kindergarten life, and how different rules and norms regulate their expression. Studying emotions from a practice perspective in everyday interaction is likely to yield new information on how emotions emerge and manifest themselves in daily life, and how different aspects of organizational cultures enable and constrain their expression.

However, understanding such a complex phenomenon as compassion requires us to go beyond the psychological and practice perspectives. In this paper, we will offer a third approach that we call the cultures of compassion perspective. Using the vignette presented at the beginning of this chapter, we illustrate these three perspectives and how compassion can be understood and interpreted differently from each perspective. We conclude the chapter by considering the implications of promoting and researching cultures of compassion in early childhood education settings.

\section{From empathy to cultures of compassion: exploring different perspectives}

The theoretical and empirical rationale for existing empirical research on compassion derives mainly from two perspectives: the psychological (Goetz, Keltner, \& Simon-Thomas, 2010) and the practice perspectives (Lilius et al., 2008; Lilius et al., 2011). In the following, we briefly explore these two perspectives on compassion and illustrate them with our vignette. We then present 
Lipponen, L., Rajala, A., Hilppö, J. (2018). Compassion and emotional worlds in early childhood education. In C. A. Pascal, T. Bertram, \& M. Veisson (Eds.), Early Childhood Education and Change in Diverse Cultural Contexts. Routledge

our own suggestion for a research program on compassion, drawing on a third perspective, namely, fostering cultures of compassion.

\section{Psychological perspective on compassion}

From a psychological perspective, compassion is understood as an emotion or as an individual skill or trait. As an emotion, it is a part of the emotion family of distress, pity, sadness, sympathy, and love. However, as indicated by Goetz and others (2010), evolutionary analysis has shown that compassion is a distinct emotion, and should not be confused with these other emotions nor with empathy, which is perhaps the closest to compassion. Compassion depends not only on the noticing of suffering, but also on the extent to which a focal actor feels empathic concern (Dutton et al., 2014; Kanov et al., 2004). Batson $(1994,606)$ defines this as "other-oriented feelings that are most often congruent with the perceived welfare of the other person." This emotional sub-process is the dominant way that psychologists have studied and defined compassion (Goetz et al., 2010). Empathic concern involves feelings of sympathy that tend to be other-oriented and altruistically—as opposed to egoistically-motivated (Batson, 1987). These feelings are a "potent source of motivation to help relieve the empathy-inducing need" (Batson et al., 2007, 65). As a trait, compassion can be understood as a general pattern of behavior, thought, or styles of emotional responses to act on the behalf of a distressed, or suffering, other. These patterns or styles persist across contexts and over time, differ across individuals, and affect behavior. 
Lipponen, L., Rajala, A., Hilppö, J. (2018). Compassion and emotional worlds in early childhood education. In C. A. Pascal, T. Bertram, \& M. Veisson (Eds.), Early Childhood Education and Change in Diverse Cultural Contexts. Routledge

Exploring and interpreting the vignette presented at the beginning of the chapter from the psychological perspective reveals clearly that both the father and the teacher strongly focus on the child to alleviate her pain and hardship. We can assume that their actions are provoked by feelings of empathy, the other-oriented feeling, and a desire to ensure/safeguard the welfare of the child. Further, understanding compassion as a trait provides a possible explanation for the father's empathy: one feels more compassion for those who are most important to one's well-being, that is, compassion enhances the welfare of vulnerable offspring. We can also assume that the teacher's the skill of reading the situation and acting in a sensitive way is based, at least partly, on her professional training and education. From a psychological perspective, for instance, there is little interest in the pattern of practices and rules the different actors are oriented towards and have enacted in this situation, or how the participants respond to and anticipate each other's actions. In short, the perspective highlights the father's and the teacher's capacities to show compassion.

Psychological studies on compassion have demonstrated that it is more difficult to feel compassion when differences exist between people in, for example, status, culture, religion, language, skin color, gender or age. These studies have also revealed that deservingness is essential to the appraisal processes that give rise to compassion, and that feeling compassion is sensitive to the possible costs involved in helping someone else (Goetz et al., 2010). Further, we feel more compassion for those who are most important to our well-being, like the father in 
Lipponen, L., Rajala, A., Hilppö, J. (2018). Compassion and emotional worlds in early childhood education. In C. A. Pascal, T. Bertram, \& M. Veisson (Eds.), Early Childhood Education and Change in Diverse Cultural Contexts. Routledge

our vignette. As Nussbaum (2014) points out, this can lead to the division of the world into "us" and "them," and compassion for one's own children can easily slip over into a desire to promote their well-being at the expense of that of others' children. In addition, the psychological perspective has been interested in how compassion develops. Researchers have focused, for example, on understanding the age at which children are capable of everyday mindreading, understanding other peoples' mental states and different emotions, and showing empathy and prosocial behavior (Eisenberg, 2003).

One central limitation of a psychological perspective is that while exclusively focusing on those who express compassion, it has mainly ignored the perspectives of those who receive compassion as well as witness it as bystanders. Research in organizational settings (practice perspective), however, shows that acts of compassions affect the participants inhabiting all these different roles, shaping how they make sense of themselves, of others, and of the organization at large (Lilius et al., 2008). Furthermore, there is a lack of studies that treat compassion as a culturally and materially constructed phenomenon, especially in early childhood settings.

\section{Practice perspective on compassion}

When reading the vignette from a practice perspective, we notice that the act of helping the child to overcome her separation anxiety can also be interpreted as a joint interactional accomplishment of the father, the kindergarten teacher, and the 
Lipponen, L., Rajala, A., Hilppö, J. (2018). Compassion and emotional worlds in early childhood education. In C. A. Pascal, T. Bertram, \& M. Veisson (Eds.), Early Childhood Education and Change in Diverse Cultural Contexts. Routledge

child herself. The shared challenge for the father and the kindergarten teacher emerges when the child expresses her difficulty with the situation, that is, the father's attempt to leave her in the kindergarten. The teacher and father act in concert, attuning themselves to what each is doing, in order to find mutually acceptable ways of understanding and alleviating the child's distress. For example, the teacher does not interfere immediately, but allows the father to first comfort the child.

The situation and the participants' interpretation of what is happening evolves moment by moment, with each action constituted as a response to previous interactions as well as in anticipation of other participants' responses. Similarly, we can see a dynamic interplay between overt actions and emotional states. When the child shows her emotional distress and clings to her father, the father suggests drawing as something the child might want to do. Although the upset of being left at kindergarten probably does not vanish immediately, the change in activity, from saying goodbye to drawing, clearly relieves the child's anguish and, thus, in practical terms, helps the child, the father and the teacher manage the distressing moment of separation.

The practice perspective, then, informs us about how compassion is constructed, emerges, and evolves in interactions between people, and in different cultural contexts. The focus can, for example, be on the following issues: which events trigger compassionate responses; who gives and who receives these responses, and in what form and under what conditions; how people talk about and make sense of compassion in their everyday lives. From a practice perspective, 
Lipponen, L., Rajala, A., Hilppö, J. (2018). Compassion and emotional worlds in early childhood education. In C. A. Pascal, T. Bertram, \& M. Veisson (Eds.), Early Childhood Education and Change in Diverse Cultural Contexts. Routledge

compassion can be regarded as a multi-dimensional process composed of three elements: noticing another person's suffering; having other-regarding empathic concern; acting to alleviate the suffering (see Lilius et al., 2008; 2011). Whereas empathy means the capacity to understand what another person is experiencing, compassion goes further in leading to actions such as helping, including, caring/comforting, sharing, and protecting others from harm and injustice.

Further, a practice perspective of compassion is not limited to the investigation of single expressions of compassion. The situation described in the vignette is most likely not the first time the teacher and father have encountered or will encounter the child's anxiety in the face of separating from the parents. On the contrary, such situations occur repeatedly. To account for the repeated nature of acts of compassion, research needs to pay attention not only to what is specific to the situation, but also to situation-transcending features of the culture of the kindergarten to which the participants are orienting. These features include appropriate times and ways of expressing and responding to emotions, division of work between the parents and the kindergarten personnel in how they deal with the issue, and rules and norms involving normative expectations. For example, in the kindergarten in question in the vignette, there was the explicit rule "Comfort children who pine for their parents." Such written rules reify and make visible what are valued and salient aspects of routinized responses to issues of daily life in kindergarten. Another example of an enabling practice would be the two-week 
Lipponen, L., Rajala, A., Hilppö, J. (2018). Compassion and emotional worlds in early childhood education. In C. A. Pascal, T. Bertram, \& M. Veisson (Eds.), Early Childhood Education and Change in Diverse Cultural Contexts. Routledge

period during which parents typically accompany their child to kindergarten in Finland when the child is first starting care.

Thus, from a practice perspective, the focus is not so much on individuals' capacity to show compassion, but instead on what kind of foundations the everyday, interactional practices of a community (e.g., an ECE community) create for compassionate actions (Lilius et al., 2011; Orlikowski, 2002). In other words, an important question is what enables the capability of the members of a community to consistently act with compassion in response to recurring instances of suffering. Settings differ in how the institutional arrangements and practices enable or constrain different aspects of compassion.

There is a body of research in organizational studies that has contributed to an understanding of how compassion can be researched as an interactional and practice phenomenon in work situations. According to Dutton et al. (2014) organizational studies on compassion reveal several factors that may trigger suffering at work. These include events in an individual's personal life, the work itself, negative interpersonal experiences at work, and different organizational actions. Lilius and colleagues (2011) identified two relational conditions that enabled employees of a business unit to notice, feel and respond to members' suffering. The first condition concerned connections of positive regard and mutuality between people. The second condition, the norm of dynamic boundarypermeability, permitted some spillover between work and other life contexts. It made possible a priority shift on occasions in which non-work demands were too 
Lipponen, L., Rajala, A., Hilppö, J. (2018). Compassion and emotional worlds in early childhood education. In C. A. Pascal, T. Bertram, \& M. Veisson (Eds.), Early Childhood Education and Change in Diverse Cultural Contexts. Routledge

overwhelming for an employee to work as usual. Further, the conditions were shown to be cultivated by a number of everyday practices in the unit, such as addressing problems directly, celebrating, collective decision-making, offering help, and orienting. Moreover, research in workplaces has shown that compassion increases positive emotions and commitment to work. It also shapes people's sense-making about themselves, others, as well as the workplace (Lilius et al., 2008).

Although empirical research on compassion from a practice perspective in ECE settings is scarce, our own work has shown that compassion-enabling arrangements can be found in current ECE institutions and practices. In our own earlier work, one of us (Lipponen, in press) conducted a study on the role rules play in the culture of compassion in ECE settings. The study was conducted in a kindergarten and it revealed that the most prevalent rule in that kindergarten was "including." This probably implies that the kindergarten in question aims to be an inclusive space in which everybody is accepted, and everyone's needs are recognized. In everyday interactions, however, most of the concrete acts of compassion were acts of comforting and caring. Holding children and taking them onto an adult's lap were so common as to appear almost as a rule that was formulated in everyday interaction as a situated practice.

The practice perspective also has implications for how we understand learning the capability for compassion. The culture and social practices of ECE settings are not 
Lipponen, L., Rajala, A., Hilppö, J. (2018). Compassion and emotional worlds in early childhood education. In C. A. Pascal, T. Bertram, \& M. Veisson (Eds.), Early Childhood Education and Change in Diverse Cultural Contexts. Routledge

simply an outside influence on the development of the capability for compassion in children. Rather, these settings constitute and mediate children's capabilities and displays of compassion (Kumpulainen \& Renshaw, 2007; Lave \& Wenger, 1991; Säljö, 1991). When education is not considered merely as the transmission of qualifications, but also as involving processes of enculturation and subjectification (Biesta, 2010), a crucial question is how compassion is manifested in the social practices of given ECE settings and how local norms, values and social relationships mediate when, where, and in what ways compassion can and should be displayed. Children develop through relationships with caregivers and educators by interpreting experience in interaction with caring adults who initiate them into communities (Vadeboncoeur \& Collie, 2015).

\section{Cultures of Compassion}

In the previous sections, we explored two research perspectives on compassion, namely, the psychological and the practice perspectives. While acknowledging the importance of these perspectives, we argue, however, that understanding such a complex phenomenon as compassion requires us to go beyond the psychological and practice perspectives. As a solution, we will offer a third approach, which we call cultures of compassion. The basic idea of our approach is that we further elaborate and develop the practice perspective with ideas from the "politics of compassion" (Ure \& Frost, 2014), and cultural historical activity theory (CHAT, Engeström, 1987). These approaches share the idea of transforming and 
Lipponen, L., Rajala, A., Hilppö, J. (2018). Compassion and emotional worlds in early childhood education. In C. A. Pascal, T. Bertram, \& M. Veisson (Eds.), Early Childhood Education and Change in Diverse Cultural Contexts. Routledge

expanding existing institutional or organizational practices and structures to harness compassion.

Central questions in the "politics of compassion" are where are acts of compassion directed or what are they directed towards; and where should acts of compassion be directed and what are they directed towards. According to Nussbaum (2014), compassion is the basic sentiment of a democratic community: without it we lack the motive to respect others, protect them from harm and respond to their undeserved sufferings. As a building block of a democratic community, compassion should operate beyond the individual emotions and relationship of the sufferer and the one who is trying to alleviate the pain. Whitebrook (2014) advocates the political nature of compassion, arguing that compassion becomes political when it identifies systemic or institutional causes of collective suffering, and then acts against these causes. It is not an exaggeration to say that compassion is a fundamental emotion and phenomenon of the emotional worlds of early childhood education.

From the activity theoretical (Engeström, 1987) point of view, tracking structures or institutional causes of collective suffering and acting against them requires exploring and understanding the historical development of these institutions, or systems, and their practices. These systems are shaped and transformed over long periods of time. Their problems and capacity to develop into something new in the future can only be understood against their own history. Another important 
Lipponen, L., Rajala, A., Hilppö, J. (2018). Compassion and emotional worlds in early childhood education. In C. A. Pascal, T. Bertram, \& M. Veisson (Eds.), Early Childhood Education and Change in Diverse Cultural Contexts. Routledge

principle that we take from CHAT to explore compassion is mediation (Vygotsky, 1978). Human beings do not live in a vacuum, but our thinking and activities are mediated through the cultural symbol systems, artifacts we use, and social mediators, such as rules and divisions of labor. Thus, to understand compassion, one should explore, for instance, rule formation as well as the practical and symbolic tools that mediate how compassion can and should be expressed in early childhood settings.

Thirdly, cultures of compassion includes the idea of interventions as a tool for social transformations. As noted by Fotaki (2015), compassion should be understood as a social phenomenon that "shapes and is shaped by conditions of inequality and coercion extending to the notion of social justice and solitary" $(2015,200)$. Fostering cultures of compassion constitutes one potential answer to the polarization of contemporary society by increasing the possibilities of what people are actually able to do and to be. Following the ideas of formative interventions (Engeström, 2011), and social design experiments (Gutiérrez \& Jurow, 2016), we aim to create more just communities and society. These methods of intervention are characterized by a collective effort to re-envision what the activity is about and to create new tools and practices to realize the enhanced vision. In contrast to top-down methods of promoting organizational change, kindergarten personnel — and even children — are considered an important catalyst of the change effort as they, in the daily practices of the kindergarten, enact change to address local needs. We also hold that a successful organizational 
Lipponen, L., Rajala, A., Hilppö, J. (2018). Compassion and emotional worlds in early childhood education. In C. A. Pascal, T. Bertram, \& M. Veisson (Eds.), Early Childhood Education and Change in Diverse Cultural Contexts. Routledge

change is a communal learning process that leads to expansion and transformation of the given ways of organizing activity within kindergartens (Cobb \& Jackson, 2012).

In comparison to the psychological and practice perspectives, the cultures on compassion perspective highlights at least three new aspects of our vignette. Firstly, one of the roots of the emotional distress experienced in the situation leads to the current arrangement of societal institutions and their functions in modern welfare societies. Historically, the responsibility of taking care of children and their education while parents work during the day has fallen to daycare institutions and thus, in part, led to the routine separation of children from their parents in the mornings. Secondly, these practices have their own developmental history within the practices of early childhood education as well as more specifically in the local practices of the kindergarten Children's House. Furthermore, various aspects of the profession of an early childhood educator, such as being emotionally available to children, have been historically valued differently. Lastly, the cultures of compassion perspective highlights that the acts of compassion demonstrated in the vignette are mediated by the symbolic and material artifacts, rules and division of labor of the Children's House. None of these issues is of course detached from the shared micro-history of the child, the father, and the teacher in question and their personal relationships.

\section{Discussion}


Lipponen, L., Rajala, A., Hilppö, J. (2018). Compassion and emotional worlds in early childhood education. In C. A. Pascal, T. Bertram, \& M. Veisson (Eds.), Early Childhood Education and Change in Diverse Cultural Contexts. Routledge

There is growing discussion of how emotions are constructed, enacted, and negotiated in social interactions in everyday life in early childhood education (Madrid, Fernie \& Kantor, 2015), but still little research on compassion exists. Further, increasing social diversity, unpredictability, and complexity have led policy makers and educationalists to look for competences, cultural practices, and politics that we need, not only in a future society, but also in our current everyday lives. Compassion or related attributes, such as social responsibility, seem to be among those competences that researchers most agree are crucial (Adamson \& Darling-Hammond, 2015; Morrell, 2010; Nussbaum, 2011).

In this chapter, we have argued that compassion is not only relevant in contemporary times characterized by constant social change but it can also be a driver of innovation and social change towards a more inclusive and just world. We have presented three perspectives for researching and understanding compassion in early education settings, namely, the psychological, practice, and cultures of compassion perspectives. We have argued that understanding such a complex phenomenon as compassion requires going beyond the psychological and practice perspectives to focus on and transform systemic or institutional causes of collective suffering. We need to harness compassion as a tool for social transformation: not only on the level of small group, face-to-face interactions (practices), but also on the level of large-scale social processes and policies. This is likely to yield informative cultural (and cross-cultural) differences in compassion related to the vocabulary of compassion, scripts, and rules that govern how compassion should be expressed, and how organizational practices and 
Lipponen, L., Rajala, A., Hilppö, J. (2018). Compassion and emotional worlds in early childhood education. In C. A. Pascal, T. Bertram, \& M. Veisson (Eds.), Early Childhood Education and Change in Diverse Cultural Contexts. Routledge

structures, and policy objectives might either foster or impede compassion. Creating cultures of compassion gives us opportunities to further develop pedagogic innovations in early childhood education as well as in cross-cultural contexts.

\section{Acknowledgements}

The research reported in this article was funded by the Academy of Finland (the project no. 299191).

\section{References}

Adamson, F., \& Darling-Hammond, L. (2015). Policy pathways for twenty-first century skills. In P. Griffin, \& E. Care (Eds.), Assessment and Teaching of 21st Century Skills: Methods and Approach (pp. 293-310). Dordrecht: Springer.

Batson, C. D. (1987). Prosocial motivation: Is it ever truly altruistic? Advances in Experimental Social Psychology, 20, 65-122.

Batson, C. D. (1994). Why act for the public good? Four answers. Personality and Social Psychology Bulletin 20, 603-610. 
Lipponen, L., Rajala, A., Hilppö, J. (2018). Compassion and emotional worlds in early childhood education. In C. A. Pascal, T. Bertram, \& M. Veisson (Eds.), Early Childhood Education and Change in Diverse Cultural Contexts. Routledge

Batson, C. D., Eklund, J. H., Chermok, V. L., Hoyt, J. L., \& Ortiz, B.G. (2007). An additional antecedent of empathic concern: Valuing the welfare of the person in need. Journal of Personality and Social Psychology, 93, 65-74.

Biesta, G. (2010). What is education for? Good education in an age of measurement: Ethics, politics, democracy. Boulder, C: Paradigm Publishers.

Cobb, P., \& Jackson, K. (2012). Analyzing educational policies: A learning design perspective. Journal of the Learning Sciences, 21, 487-521.

Dutton, J., Workman, K., \& Hardin, A. (2014). Compassion at work. The Annual Review of Organizational Psychology and Organizational Behavior, 1, 277-304.

EDUFI (2016). National core curriculum for early childhood education and care. Tampere: Suomen yliopistopaino.

Eisenberg, N. (2013). The development of prosocial behavior. New York: Academic Press.

Engeström, Y. (1987). Learning by expanding. Helsinki: Orienta-Konsultit.

Engeström, Y. (2011). From design experiments to formative interventions. Theory \& Psychology, 21, 598-628. 
Lipponen, L., Rajala, A., Hilppö, J. (2018). Compassion and emotional worlds in early childhood education. In C. A. Pascal, T. Bertram, \& M. Veisson (Eds.), Early Childhood Education and Change in Diverse Cultural Contexts. Routledge

Fotaki, M. (2015). Why and how is compassion necessary to provide good quality healthcare? International Journal of Health Policy Management, 4, 199-201.

Frost, P. J., Dutton, J. E., Worline, M. C., \& Wilson, A. (2000). Narratives of compassion in organizations. In. S. Fineman, (Ed.), Emotions in organizations (pp. 25-45). California: Sage Publications.

Goetz, L., Keltner, D., \& Simon-Thomas, E. (2010). Compassion: An evolutionary analysis and empirical review. Psychological Bulletin, 36, 351-374.

Gutiérrez, K., \& Jurow, S. A. (2016). Social design experiments: Toward equity by design. Journal of the Learning Sciences, 26, 1-34.

Kanov, J., Maitlis, S., Worline, M., Dutton, J. Frost, P., \& Lilius, J. (2004). Compassion in organizational life. American Behavioral Scientist, 47, 808-827.

Kumpulainen, K., \& Renshaw, P. (2007). Cultures of learning. International Journal of Educational Research, 46, 109-115.

Lilius, J., Worline, M., Maitlis, S., Kanov, J., Dutton, J., \& Frost, P. (2008). The contours and consequences of compassion at work. Journal of Organizational Behavior, 29, 193-218

Lilius, J., Worline, M., Dutton, J., Kanov, J., \& Maitlis, S. (2011). Understanding compassion capability. Human Relations, 64, 873-899. 
Lipponen, L., Rajala, A., Hilppö, J. (2018). Compassion and emotional worlds in early childhood education. In C. A. Pascal, T. Bertram, \& M. Veisson (Eds.), Early Childhood Education and Change in Diverse Cultural Contexts. Routledge

Lave, J., \& Wenger, E. (1991). Situated learning: Legitimate peripheral participation. Cambridge, MA: Cambridge University Press.

Lipponen, L. (in press). Constituting cultures of compassion in early childhood educational settings. In S. Garvis (Ed.), Nordic Children and Families. Routledge.

Madrid, S., Fernie, D., \& Kantor, R. (2015). Introduction to reframing emotions. In S. Madrid, D. Fernie, \& R. Kantor (Eds.), Reframing the emotional worlds of the early childhood classroom (pp. 1-15). New York: Routledge.

Morrell, M. (2010). Empathy and democracy: Feeling, thinking, and deliberation. Penn State Press.

Nussbaum, M. (2011). Creating capabilities. Harvard University Press.

Nussbaum, M. (2014). Compassion and terror. In M. Ure, \& M. Frost (Eds.), The politics of compassion (pp. 89-207). New York: Routledge.

OECD. (2015). Skills for social progress: The power of social and emotional skills. OECD Skills Studies. OECD Publishing.

OECD. (2016). Global competency for an inclusive world. Retrieved 22nd of June, https://www.oecd.org/education/Global-competency-for-an-inclusiveworld.pdf. 
Lipponen, L., Rajala, A., Hilppö, J. (2018). Compassion and emotional worlds in early childhood education. In C. A. Pascal, T. Bertram, \& M. Veisson (Eds.), Early Childhood Education and Change in Diverse Cultural Contexts. Routledge

Orlikowski, W. J. (2002). Knowing in practice: Enacting a collective capability in distributed organizing. Organization Science, 13, 249-273.

Paananen, M. (In press). Rubik's cube effect and imaginaries of early childhood education. Global Studies of Childhood.

Paananen, M., \& Lipponen, L. (In press). Pedagogical documentation as a lens for equality in ECE. Early Child Development and Care.

Rynes, S. L., Bartunek, J. M., Dutton, J. E., \& Margolis, J. D. (2012). Care and compassion through an organizational lens: Opening up new possibilities. Academy of Management Review, 37, 503-523.

Stetsenko, A. (2008). From relational ontology to transformative activist stance on development and learning: Expanding Vygotsky's (CHAT) project. Cultural Studies of Science Education, 3, 471-491.

Säljö, R. (1991). Learning and mediation: Fitting reality into a table. Learning and Instruction, 1, 261-272.

Tronto, J. C. (2013). Caring democracy: markets, equality, and justice. NYU Press. 
Lipponen, L., Rajala, A., Hilppö, J. (2018). Compassion and emotional worlds in early childhood education. In C. A. Pascal, T. Bertram, \& M. Veisson (Eds.), Early Childhood Education and Change in Diverse Cultural Contexts. Routledge

Ure, M, \& Frost, M. (Eds.) (2014). The politics of compassion. New York: Routledge.

Vygotsky, L. S. (1978). Mind in society: The development of higher psychological processes. Harvard University Press, Cambridge, MA.

Whitebrook, M. (2014). Love and anger as political virtues. In M. Ure, \& M. Frost (Eds.), The Politics of Compassion (pp. 21-36). New York: Routledge. 